\section{Шитова Е.П.}

аспирант ФГБВОУ ВО «Академия гражданской защиты МЧС России», аналитик, ФГБОУ ВО «Государственный университет управления», г. Москва

e-mail: eva1899@mail.ru

\section{Shitova E.P.}

Postgraduate student, The Civil Defence Academy of the Ministry of the Russian Federation for Civil Defense, Emergencies and Elimination of Consequences of Natural Disasters, analyst, State University of Management, Moscow

e-mail: eva1899@mail.ru

\section{Влияние публичных слушаний на принятие решений по объединению муниципальных образований в Московской области}

\begin{abstract}
Аннотация
Рассмотрена практика применения публичных слушаний в Московской области при преобразовании муниципальных образований за период 2015-2018 гг. В связи с изменениями в российском законодательстве в последние годы публичные слушания стали обязательным элементом взаимодействия граждан и представителей муниципальных образований при объединении муниципалитетов. Цель статьи состоит в определении фрактического влияния граждан, их мнения, внесенных ими предложений, выражения согласия или несогласия по рассматриваемому на слушаниях вопросу на итоговое решение. Для этого проведен анализ протоколов и заключений публичных слушаний, определены основные характеристики данной формы участия населения в осуществлении местного самоуправления. Приведены статистические данные о среднем количестве участников публичных слушаний по вопросам преобразования муниципальных районов в городские округа, времени на подготовку к ним в масштабе 20 муниципальных образований Московской области, результатах голосования граждан, присутствии на слушаниях представителей государственной власти и некоторых других характеристиках. Также проведено исследование аргументации «за» и «против» объединения, определены некоторые противоречия в точках зрения представителей муниципальной власти по вопросам преобразований. По результатам исследования дана оценка публичным слушаниям как форме демократического участия граждан в осуществлении местного самоуправления на основании ее практической реализации в Московской области, определены ситуации, при которых мнение населения способно скорректировать предполагаемый исход преобразований. В частности, сделан вывод о достаточно высоком проценте посещаемости гражданами слушаний, отсутствии в большинстве случаев единого мнения по поводу объединения муниципалитетов у граждан, и, напротив, однозначно положительной оценке преобразований со стороны муниципальной власти. Также предполагается, что наиболее редкий сценарий - отмена объединения муниципалитетов под влиянием публичных слушаний - возможен в большей степени для сельских поселений с высокой инициативностью населения.
\end{abstract}

Ключевые слова:

объединение муниципальных образований, публичные слушания, Московская область, местное самоуправление, участие населения, демократия, взаимодействие власти с населением.

\section{The impact of public hearings on decision making on the merger of municipalities in the Moscow region}

\begin{abstract}
The practice of applying public hearings in the Moscow region in the transformation of municipalities for the period 2015-2018 has considered. In connection with changes in Russian legislation in recent years, public hearings have become an indispensable element of the interaction of citizens and municipal authorities when merging municipalities. The purpose of this article is to determine the actual influence of citizens, their opinions, suggestions made by them, the expression of consent or disagreement on the issue being considered at the hearing on the final decision. For this purpose, an analysis of the protocols and conclusions of public hearings has conducted, the main characteristics of this form of public participation in the implementation of local self-government have determined. Statistical data on the average number of participants in public hearings on the transformation of municipal districts into urban districts, time to prepare for them in the scale of 20 municipalities of the Moscow region, the results of citizens 'voting, the presence of representatives of state authorities and some other characteristics have provided. Also, a study of the arguments "for" and "against" the association has conducted, some contradictions in the points of view of representatives of the municipal government on the issues of transformations have identified. According to the results of the study, an assessment has made of public hearings as a form of democratic participation of citizens in the implementation of local self-government on the basis of its practical implementation in the Moscow region, and situations have identified in which the opinion of the population is able to correct the intended outcome of the changes. In particular, a conclusion has made about a fairly high percentage of citizens' attendance at hearings, the absence in most cases of a unanimous opinion about the association of municipalities among citizens, and, on the contrary, a uniquely positive assessment of changes by the municipal government. It is also assumed that the most rare scenario - the abolition of the merger of municipalities under the influence of public hearings - is possible to a greater extent for rural settlements with a high initiative of the population.
\end{abstract}

Keywords:

merger of municipalities, public hearings, Moscow region, local government, public participation, democracy, government interaction with the population.

(C) The Author(s), 2018 This is an open access article under the CC BY 4.0 license (http://creativecommons.org/ licenses/by/4.0/) 
В Московской области на данный момент продолжается административная реформа местного самоуправления, суть которой заключается в количественном сокращении муниципалитетов за счет их объединения и преобразования преимущественно в городские округа [5].

В период с января 2015 г. по июль 2018 г. количество муниципальных образований в Московской области сократилось на 183 и по-прежнему продолжает уменьшаться [8]. Во многом для упрощения процедуры преобразования муниципального района (с ликвидацией входящих в него поселений) в городской округ Государственной Думой Российской Федерации были приняты поправки (от 03.04.2017) в Федеральный закон 131-Ф3 от $06.10 .2003 »$ [ $1 ; 2]$.

В частности, пункт 3.1. статьи 13 этого закона в предыдущей редакции не предусматривал возможности объединения всех поселений муниципального района, как и вообще процедуры утраты муниципальным районом статуса муниципального образования. Пункты 7 и 7.2 статьи 13 - полностью убрано положение о проведении процедуры голосования местного населения для принятия решения о преобразовании муниципального района. В новой редакции это положение заменено голосованием представительного органа. Теперь для преобразования не требуется проведение местного референдума, достаточно публичных слушаний (далее - ПС) и голосования местного совета депутатов.

Как можно заметить, ПС в процедуре преобразования муниципалитетов являются единственным способом выявления мнения населения и взаимодействия граждан с муниципальной властью. По мнению некоторых исследователей, принимаемые на ПС решения хотя и носят рекомендательный характер для органов власти, но обязательны для рассмотрения и учета при принятии соответствующего решения [6]. Слушания не являются формой прямой или представительной демократии, такой как референдум, выборы или сход граждан не сопоставимы с ними по правовой силе. Публичные слушания - форма консультативной демократии, при которой обеспечивается лишь участие отдельных граждан в муниципальной деятельности, а волеизъявление индивидов не имеет верховного значения для органов местного самоуправления [7].

Проблема в данном случае видится автору в том, что в некоторых ситуациях слушания могут превращаться в формальный инструмент для осуществления необходимых власти преобразований и не оказывать никакого влияния на результат.
Наиболее ярко подобное проявляется при расхождении мнения граждан и решения представительного органа.

\section{Цель исследования}

С помощью анализа процесса организации и проведения ПС хотелось бы понять, какое влияние они оказывают на итоговое принятие решения по объединению. Есть ли это влияние вообще? Если оно минимально, то каковы причины подобного сценария? В каких ситуациях влияние населения способно скорректировать или полностью изменить предполагаемый исход событий? В качестве гипотезы выдвигается предположение о достаточно слабом влиянии населения на итоговый результат в связи с отсутствием правовых рычагов, позволяющих данной форме взаимодействия с властью произвести достаточный эффект, а также низким показателем вовлеченности граждан в сам процесс проведения слушаний.

\section{Методология исследования}

Источником информации для анализа послужили документы муниципальных образований - заключения и протоколы ПС. В статье рассмотрены только те муниципалитеты, протоколы которых можно найти в свободном доступе. К сожалению, после объединения поселений сайты многих упраздненных муниципалитетов прекращают функционировать и ознакомиться с их документами невозможно. Всего исследованы протоколы и/или заключения слушаний по 20 муниципальным образованиям Московской области.

В первой части исследования проводилась статистическая обработка нескольких формальных показателей, позволяющих представить картину проведения ПС, например, сколько часов затрачивается на их проведение, сколько дней отводится на подготовку к ним, количество участников и др.

Во второй части проводился анализ вопросов, аргументов, мнений, непосредственно рассматриваемых во время проведения слушаний, по сути, контент-анализ протоколов ПС. Нас интересует такая характеристика текстов, как эмоциональный тон - «за» или «против» объединения участники слушаний. Второй момент - наиболее часто встречающиеся аргументы населения и представителей власти, подтверждающие их точку зрения по поводу преобразований.

Таким образом, мы получили представление о формальной и содержательной сторонах ПС и определили влияние мнений граждан на местное самоуправление в рамках своих поселений и общую 
результативность такой формы взаимодействия власти с населением.

\section{Оценка формальных характеристик проведения публичных слушаний}

В таблицах 1 и 2 последовательно приведены характеристики ПС в сельских и городских поселениях, а также городских округах (в тексте статьи используются сокращения с.п., г.п. и г.о. соответственно). Разделение на две группы связано с невозможностью корректно объединить статистические показатели сельских и городских поселений в части количества участников ПС, численного подсчета голосовавших и присылавших письменные заявления и предложения из-за разницы в общем количестве населения данных типов муниципальных образований.

Для понимания масштаба ПС как одной из форм взаимодействия муниципальной власти с населением стоит обратить внимание на количество участников. По вышеуказанным данным для сельских поселений это число колеблется от 26 (минимум) до 307 (максимум), среднее значение составляет
108 человек. Если рассматривать количество участников публичных слушаний в виде процента от населения, то оно составит в среднем около $2 \%$. Максимальное значение, достигнутое по данному пункту, в нашем случае составляет 3,8 \% (с.п. Рыболовское).

Далее оценим временные характеристики организации и проведения публичных слушаний. Количество дней, в которые осуществляется подготовка к публичным слушаниям сельских поселений, находится в интервале от 5 до 37, среднее значение - 24 . Период около трех недель можно считать достаточным для организации слушаний и донесения информации до жителей. Существующие на данный момент технологии позволяют оповестить жителей населенного пункта с населением в несколько тысяч человек за такое время. Вопрос о результативности реально применяемых средств оповещения населения органами муниципальной власти пока оставим открытым. Слабое информирование граждан как проблема местного самоуправления рассматривалось в некоторых других исследованиях [3; 4].

Характеристики публичных слушаний в различных сельских поселениях Московской области

\begin{tabular}{|c|c|c|c|c|c|c|c|c|}
\hline $\begin{array}{l}\text { Название сельского поселения } \\
\text { муниципального района }\end{array}$ & 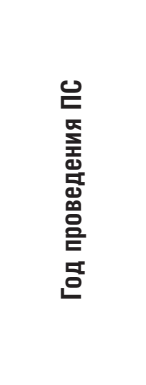 & 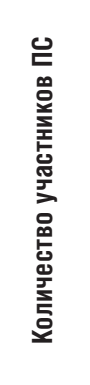 & 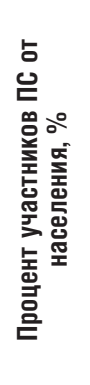 & 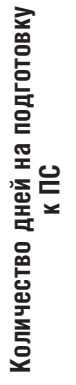 & 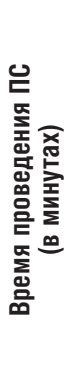 & 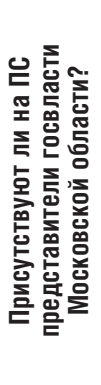 & 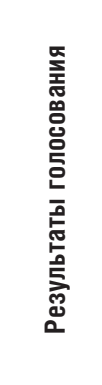 & 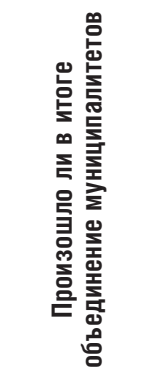 \\
\hline $\begin{array}{l}\text { Березняковское Сергиево-Посадского } \\
\text { микрорайона (далее - м.р.) }\end{array}$ & 2018 & 26,0 & 0,384 & 28 & 120 & Нет & 3a & В процессе \\
\hline Габовское Дмитровского м.р. & 2017-2018 & 307,0 & 3,239 & 37 & 90 & Нет & $3 a$ & Да \\
\hline Ермолинское Талдомского м.р. & 2016 & 41,0 & 1,939 & 23 & 30 & Да & $3 a$ & Да \\
\hline Ивановское Истринского м.р. & 2016 & 78,0 & 2,687 & 27 & - & Да & Против & Да \\
\hline Кривандинское Шатурского м.р. & 2016 & 44,0 & 0,526 & 34 & 60 & Нет & 3a & Да \\
\hline Луневское Солнечногорского м.р. & 2018 & - & - & 15 & 120 & Нет & Против & Нет \\
\hline Микулинское Лотошинского м.р. & 2017 & 47,0 & 1,376 & 5 & 120 & Да & - & Нет \\
\hline Пышлицкое Шатурского м.р. & 2016 & 92,0 & 2,55 & 33 & 60 & Нет & 3a & Да \\
\hline Рыболовское Раменского м.р. & 2017 & 205,0 & 3,773 & 34 & 180 & Нет & - & Нет \\
\hline Соколовское Солнечногорского м.р. & 2017 & - & - & 17 & 180 & Нет & Против & Нет \\
\hline Степановское Ногинского м.р. & 2017 & 133,0 & 1,665 & 15 & 150 & Да & - & Да \\
\hline Среднее значение & - & 108,1 & 2,02 & 24,4 & 111 & - & - & - \\
\hline
\end{tabular}

Составлено автором по материалам протоколов и заключений публичных слушаний муниципальных образований [9] 
В соответствии с протоколами общее время на доклады, выступления и вопросы при проведении публичных слушаний составляет 30-180 минут, в среднем около двух часов. Скорее всего, слушания могут закончиться как раньше, так и позже запланированного времени, в таблице же представлены официально заявленные характеристики. Таким образом, за два-три часа предполагается выявить мнение населения по вопросам объединения муниципальных образований.

Следующий пункт касается наличия представителей от государственной власти региона на публичных слушаниях. В 4 протоколах из 11 была информация о присутствии на слушаниях депутатов Московской областной Думы, сотрудников Правительства Московской области или даже представителей федерального уровня государственной власти. При этом если в протоколе данные представители не указаны, это не говорит о том, что их не могло быть на публичных слушаниях.

Большинство сельских поселений по результатам слушаний провели голосование. Жители 5 из 11 поселений высказались «за» преобразование, в 3 муниципалитетах - «против», также в протоколах еще 3 не было указано никаких результатов голосования. Особое значение имеет то влияние, которое оказали итоги слушаний на принятие решения об объединении. Как видно из таблицы 1 , были преобразованы 6 из 11 поселений, 1 все еще находится в стадии обсуждения (на октябрь 2018 г.), в 4 случаях объединение не состоялось, причем 2 из 4 поселений относятся к одному муниципальному району - Солнечногорскому.

Сопоставив результаты голосования на публичных слушаниях и итоговые преобразования, получим следующее:

1) противоречие возникло в случае с.п. Ивановское, в котором мнение жителей не было учтено;

2) в двух других случаях голосования «против» объединение не состоялось;

3) также не произошло преобразований еще двух муниципалитетов, в протоколах публичных слушаний которых не были отмечены результаты голосования;

4) во всех остальных случаях объединение произошло без расхождения с результатами публичных слушаний.

Далее перейдем к территориально более крупным типам муниципальных образований - городским поселениям и округам (табл. 2). Рассмотрим их характеристики, в том числе в сравнении с сельскими поселениями из таблицы 1.

Таблица 2

\begin{tabular}{|c|c|c|c|c|c|c|c|c|}
\hline $\begin{array}{c}\text { Название городского поселения муниципального } \\
\text { района или городского округа }\end{array}$ & 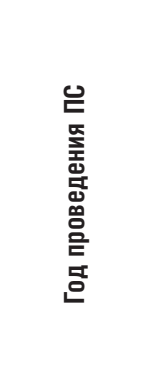 & 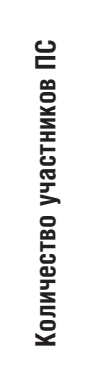 & 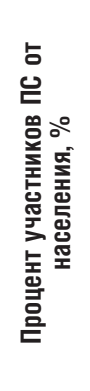 & 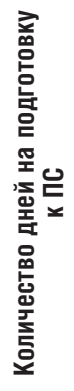 & 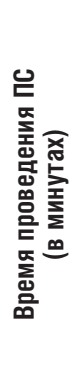 & 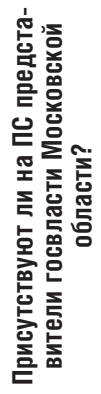 & 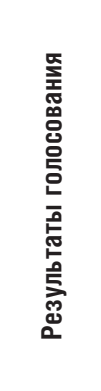 & 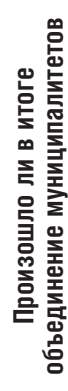 \\
\hline Дмитров Дмитровского м.р. & $2017-2018$ & 245 & 0,29 & 30 & 100 & Нет & 3a & Да \\
\hline Запрудня Талдомского м.р. & 2016 & 612 & 4,836 & 33 & - & Нет & Против & Да \\
\hline Красково Люберецкого м.р. & 2016 & 357 & 1,276 & 39 & 120 & Да & 3a & Да \\
\hline Лосино-Петровский & 2017 & 84 & 0,331 & 11 & 60 & Нет & $3 a$ & Да \\
\hline Люберцы Люберецкого м.р. & 2016 & 627 & 0,329 & 32 & 130 & Да & 3a & Да \\
\hline Ногинск Ногинского м.р. & 2017 & 266 & 0,255 & 35 & 120 & Да & 3a & Да \\
\hline Г.о. Подольск & 2015 & 850 & 0,38 & 27 & - & Нет & $3 a$ & Да \\
\hline $\begin{array}{l}\text { Солнечногорск } \\
\text { Солнечногорского м.р. }\end{array}$ & 2017 & 275 & 0,464 & 39 & - & Нет & За & Нет \\
\hline Старая Купавна Ногинского м.р. & 2017 & 715 & 2,226 & 35 & - & Нет & $3 a$ & Да \\
\hline Среднее значение & - & 447,9 & 1,15 & 31,2 & 106 & - & - & - \\
\hline
\end{tabular}

Составлено автором по материалам протоколов и заключений публичных слушаний муниципальных образований [10]. 
Итак, количество участников публичных слушаний в городских поселениях в среднем почти в 4 раза превышает аналогичный показатель из таблицы 1. Максимальное значение в данном случае составляет 850 человек, минимальное - 84. Однако в переводе данных значений в процент от населения в среднем получаем более низкий результат, чем в случае с сельскими поселениями $-1,15 \%$.

Для организации публичных слушаний в городских поселениях (округах) тратится по среднему значению на 6 дней больше, чем в сельских поселениях - 31 день. Количество часов, выделенных непосредственно на проведение слушаний, колеблется от 60 до 130 минут. Как видно из таблицы 2, в протоколах многих публичных слушаний не был указан временной интервал их проведения.

Как минимум треть публичных слушаний проходила в присутствии представителей государственной власти, в основном депутатов Московской областной Думы. Стоит сказать, что в протоколах (как городских, так и сельских поселений) они упоминаются не как слушатели, а как выступающие, выражающие свое положительное отношение к объединению муниципалитетов и в некоторых случаях отвечающие на вопросы местных жителей.

Жители 8 из 9 городских поселений и округов поддержали на слушаниях идею преобразования. Здесь заметна разница в значениях этого параметра для разных видов муниципалитетов: 89 \% положительных голосований для городских и 45 \% для сельских поселений. По-видимому, это соответствует тому, что жители территориально более крупных и самостоятельных муниципалитетов чувствуют сравнительно большую выгоду от объединения. Городские поселения чаще являются центром муниципального района и становятся основой для новообразованных городских округов. В этом отношении население городских поселений может быть в большей степени склонно к одобрению преобразований. Как видно из таблицы 2 , все городские поселения и округа были в итоге преобразованы, кроме муниципалитетов Солнечногорского района - в нем проголосовали против объединения некоторые сельские поселения (см. табл. 1).

\section{Контент-анализ выступлений представителей муниципальной власти и граждан на публичных слушаниях}

В таблице 3 представлены результаты анализа докладов, вопросов и мнений граждан, местных и областных депутатов, глав администраций и других участников публичных слушаний. Контентанализ проведен отдельно для двух категорий выступающих: населения и представителей органов муниципального образования. Также, помимо данных категорий, он разделен на два блока. В первом блоке определяется «эмоциональный тон» - то, как выступающие относятся к преобразованиям. Помимо положительной или отрицательной оценки для граждан есть графа «Вопросы о возможных проблемах после объединения». В данном случае эта графа показывает общий уровень беспокойства населения по поводу негативного развития событий после преобразований.

В первом блоке подсчет ведется в количестве муниципальных образований, в протоколе слушаний которых указано мнение конкретных граждан с определенной смысловой окраской. Например, если глава муниципалитета на слушаниях высказал свое положительное мнение по поводу преобразований, то 1 балл добавлялся в графу «за объединения» справа в таблице 3. Если же в протоколе указан только общий результат по группе людей (например, большинство присутствующих проголосовало «за»), то никаких баллов не добавляем: такой обобщенный итог слушаний уже отражен в таблицах 1 и 2. Здесь нас интересует исключительно смысловая окраска индивидуальных мнений.

Во втором блоке представлены основные аргументы «за» и «против» объединения муниципалитетов также по двум категориям. Отбор аргументов происходил по частоте упоминания в протоколах публичных слушаний разных муниципальных образований.

Рассмотрим результаты контент-анализа также по двум блокам. В первом блоке наблюдается превосходство положительного мнения у представителей муниципальной власти по поводу преобразований (12 из 20). По остальным муниципалитетам в протоколах слушаний либо не указано мнение представителей органов муниципального образования, либо есть только заключения, но нет протоколов публичных слушаний (в заключениях не приводятся фрагменты выступлений).

Среди населения, участвующего в слушаниях, меньше единодушия. Почти во всех случаях гражданами задавались вопросы, предполагающие возможные проблемы после объединения, мнения «за» и «против» практически равнозначны. Зачастую противоположные мнения по поводу преобразований озвучивались участниками слушаний в рамках одного муниципального образования.

Вопросы, поднимаемые гражданами на слушаниях, касались не только непосредственно планируемого объединения муниципалитетов, но и любых других проблемных вопросов поселений - от строительства жилья и ремонта дорог до экологии. 
Контент-анализ содержания протоколов и заключений публичных слушаний

\begin{tabular}{|c|c|c|c|c|c|c|}
\hline \multicolumn{4}{|c|}{ Вопросы и мнения граждан муниципалитета (населения) } & \multicolumn{3}{|c|}{ Аргументы представителей органов муниципального образования } \\
\hline $\begin{array}{l}\text { О возможных } \\
\text { проблемах } \\
\text { после } \\
\text { объединения }\end{array}$ & $\begin{array}{l}\text { В под-держку } \\
\text { объеди-нения }\end{array}$ & $\begin{array}{l}\text { Против } \\
\text { объединения }\end{array}$ & $\begin{array}{l}\text { Отсутствуют в } \\
\text { протоколе или } \\
\text { заключении } \\
\text { публичных } \\
\text { слушаний }\end{array}$ & За объединение & Против объединения & $\begin{array}{l}\text { Отсутствуют } \\
\text { в протоколе или } \\
\text { заключении } \\
\text { публичных } \\
\text { слушаний }\end{array}$ \\
\hline $\begin{array}{l}10 \text { из } 20 \\
(50 \%)\end{array}$ & $\begin{array}{l}6 \text { из } 20 \\
(30 \%)\end{array}$ & $\begin{array}{c}5 \text { из } 20 \\
(25 \%)\end{array}$ & $\begin{array}{l}10 \text { из } 20 \\
(50 \%)\end{array}$ & $\begin{array}{l}12 \text { из } 20 \\
(60 \%)\end{array}$ & $\begin{array}{l}0 \text { из } 20 \\
(0 \%)\end{array}$ & $\begin{array}{l}8 \text { из } 20 \\
(40 \%)\end{array}$ \\
\hline \multicolumn{2}{|c|}{ Основные аргументы «за» } & \multicolumn{2}{|c|}{ Основные аргументы «против» } & \multicolumn{2}{|c|}{ Основные аргументы «за» } & $\begin{array}{l}\text { Основные } \\
\text { аргументы } \\
\text { «ротив» }\end{array}$ \\
\hline \multicolumn{2}{|c|}{$\begin{array}{l}\text { Экономия бюджетных средств } \\
\text { и ускорение решения всех } \\
\text { вопросов } \\
\text { Объединение позволит } \\
\text { реализовывать новые } \\
\text { программы } \\
\text { Появится больше возможно- } \\
\text { стей для благоустройства } \\
\text { территорий }\end{array}$} & \multicolumn{2}{|c|}{$\begin{array}{l}\text { Уменьшение представителей от } \\
\text { населения (депутатов) } \\
\text { Назначение руководителей } \\
\text { территориальных управлений без } \\
\text { участия жителей } \\
\text { Сомнения по поводу достоверности } \\
\text { обещаний от глав муниципалитетов, } \\
\text { которые после объединения сложат } \\
\text { свои полномочия } \\
\text { На момент публичных слушаний нет } \\
\text { никаких гарантий (планов, } \\
\text { дорожных карт, документов) о } \\
\text { равнозначном распределении } \\
\text { финансов между объединенными } \\
\text { территориями } \\
\text { Дистанцирование органов местного } \\
\text { самоуправления от граждан }\end{array}$} & \multicolumn{2}{|c|}{$\begin{array}{l}\text { Единые тарифы на услуги ЖКХ, создание } \\
\text { единой организации тепло- и водоснабжения } \\
\text { и др. } \\
\text { Единый бюджет - более эфффективный } \\
\text { контроль за расходованием бюджетных } \\
\text { средств } \\
\text { Больше внимание будет уделяться благо- } \\
\text { устройству, социальной срере } \\
\text { Повышение инвестиционной привлекатель- } \\
\text { ности объединенного муниципалитета; } \\
\text { Управленческие процедуры значительно } \\
\text { упростятся } \\
\text { «Доступность власти» останется такой же } \\
\text { из-за создания территориальных управлений } \\
\text { вместо бывших администраций } \\
\text { Произойдет сокращение административно- } \\
\text { управленческого аппарата и, в связи с этим, } \\
\text { сокращение расходов бюджета } \\
\text { Единство/централизация органов управле- } \\
\text { ния } \\
\text { Создание комплексного плана развития } \\
\text { территории } \\
\text { Повышается вероятность участия в } \\
\text { федеральных и областных программах }\end{array}$} & Нет \\
\hline
\end{tabular}

Составлено автором по материалам протоколов и заключений публичных слушаний муниципальных образований [9; 10]

Стоит сказать, таких вопросов, отклоняющихся от основной темы слушаний, было много. Можно предполагать некоторую потребность населения в более частом и расширенном диалоге с представителями местной власти.

Во втором блоке приведены основные аргументы «за» и «против» объединения муниципалитетов. В связи с тем, что в протоколах мнение представителей органов муниципального образования было либо положительным, либо не описывалось, последняя графа в таблице 3 осталась пустой. Противоположная ей графа «за объединение» представлена наибольшим количеством аргументов в сравнении с остальными. Хотелось бы отметить, что основные плюсы преобразований действительно неоднократно повторяются на различных публичных слушаниях.
В протоколах слушаний двух муниципалитетов Дмитровского муниципального района (с.п. Габовское и г.п. Дмитров) аргументы, выдвигаемые главами поселений, повторяются дословно. То же самое наблюдается в протоколах сельских поселений Кривандинское и Пышлицкое Шатурского муниципального района. Обратим внимание, в этих случаях не просто близкие по смыслу аргументы или слегка видоизмененные формулировки, а их полная текстовая идентичность. По-видимому, в рамках одного района при проведении слушаний у глав муниципалитетов существовала некоторая договоренность по поводу аргументации причин объединения. Однако дословное копирование одного и того же текста для разных (территориально, по количеству населения, по типу) муниципалитетов вызывает определенные сомнения в достоверности 
проводимого муниципалитетами анализа по необходимости объединения.

Также существует довольно много противоречивых и спорных аргументов с обеих сторон. Приведем несколько таких примеров:

1. Некоторые представители местной власти объясняют небольшое количество участников слушаний не плохо проведенной работой по информированию населения, а доверием жителей в связи с качественно проведенной информационной работой по объяснению необходимости преобразований. Учитывая то, что обычно оповещение о публичных слушаниях ограничивается объявлением даты их проведения в местной газете и на сайте муниципалитета, довольно сложно предполагать сколько-нибудь массовый охват аудитории.

2. Глава городского поселения Люберцы В. П. Ружицкий во время проведения слушаний прокомментировал будущие преобразования так: «По сути, происходит возвращение к модели исполкома в грубом варианте».

Депутат Московской областной думы И. Н. Жуков, присутствующий на слушаниях в Ногинске, отметил следующее: «По согласованию с Президентом Российской Федерации в Московской области проходит реформа местного самоуправления. Я постоянно участвую во встречах с населением. И в большинстве случае жители поддерживают реформу вертикали власти».

Два этих высказывания объединяет указание на заинтересованность государственной власти в данных преобразованиях и ее прямое или косвенное вмешательство в процессы, происходящие на местном уровне. Муниципальная власть, заявленная Конституцией РФ (ст. 12) как самостоятельная форма публичной власти, не относится к системе государственной власти и самостоятельна в пределах своих полномочий. Исполкомы, упоминаемые Ружницким, относились к разным уровням государственной власти, в том числе занимались вопросами на местном уровне. По-видимому, данная реформа действительно стремится к подобному варианту.

3. В некоторых случаях на вопросы граждан о тарифах (ЖКХ) утверждается, что они не изменятся или, как минимум, не повысятся (например, протокол слушаний с.п. Степановское и Березняковское). В других же речь идет о едином тарифе для всей объединенной территории (протокол слушаний с.п. Пышлицкое и др.).

Также некоторой особенностью аргументации муниципальной власти «за» объединение является большое количество перечислений того, что не изменится после преобразований: не будут отменены сельские льготы, не нужно менять документы, муниципальные бюджетные учреждения продолжат работу.
В некотором смысле такие аргументы вызывают положительный отклик, хотя по факту они являются нейтральными и не несут каких-либо изменений для жителей муниципалитета.

\section{Выводы}

1. Стоит обратить внимание, что представители органов муниципальной власти в подавляющем большинстве случае поддерживают объединение муниципалитетов. Даже если это противоречит их прямым интересам, т.к. большинство действующих глав и депутатов сельских и городских поселений после преобразований теряют свои должности. Кроме того, аргументы за объединение, высказываемые руководителями муниципалитетов на слушаниях по большей части одинаковы, иногда дословно повторяют друг друга. Кроме их смысловой схожести стоит отметить достаточную обобщенность данных аргументов, отсутствие подготовленных планов преобразования или аналитики, подтверждающей реалистичность обещанных улучшений.

2. Участие граждан в публичных слушаниях в целом можно назвать успешным, что не совсем предполагалось первоначальной гипотезой данного исследования. Почти во всех рассматриваемых муниципалитетах на слушаниях было достаточно большое количество участников. Нельзя сказать, что граждане совершенно не обозначили своего мнения. Часто при голосовании по поводу объединения мнения граждан одного поселения сильно расходились, иногда результаты составляли условно $60 \%$ - за, $40 \%$ - против. Однако не всегда результаты слушаний влияли на итоги преобразований. По данным исследования были случаи как игнорирования мнения граждан, так и его учета. Отличительной особенностью случаев, когда мнение граждан было учтено, являлось практически стопроцентное высказывание гражданами мнения против объединения. Более неоднозначные случаи голосования населения заканчивались объединением муниципалитетов.

3. Однако даже полное отрицание гражданами необходимости преобразований на слушаниях не гарантирует аналогичного результата при голосовании местных депутатов по этому вопросу. В связи с тем, что слушания не наделены для этого достаточными правовыми характеристиками, отрицательное решение по объединению может быть принято только при совпадении мнений как граждан, так и представительного органа муниципального образования. По результатам нашего исследования подобный сценарий в большей степени реализован сельскими поселениями с высокой инициативностью населения. 


\section{Библиографический список}

1. Федеральный закон от 06.10.2003 № 131-Ф3 «Об общих принципах организации местного самоуправления в Российской Федерации» (ред. от 27.12.2018) [Электронный ресурс]. - Режим доступа: http://www.consultant.ru/ (дата обращения: 28.10.2018).

2. Федеральный закон от 03.02.2015 № 8-Ф3 «О внесении изменений в статьи 32 и 33 Федерального закона «Об основных гарантиях избирательных прав и права на участие в референдуме граждан Российской Федерации» и Федеральный закон «Об общих принципах организации местного самоуправления в Российской Федерации» [Электронный ресурс]. Режим доступа: http://www.consultant.ru/ (дата обращения: 28.10.2018).

3. Зуйкина, А. С. Публичные слушания: процедурные правила и результаты проведения (на примере города Перми) / А. С. Зуйкина, В. Л. Никитина // Ars Administrandi (Искусство управления). - 2018. - Т. 10, № 3. - C. 502-518.

4. Матренина, К. Ю. Электронные публичные слушания как дополнительный механизм проведения публичных слушаний // Вестник Тюменского государственного университета. Социально-экономические и правовые исследования. - 2012. - № 3. - С. 112-115.

5. Очеретина, М. А. Понятие и типология института публичных слушаний / М. А. Очеретина // Научный ежегодник Института философии и права Уральского отделения Российской академии наук. - 2008. Вып.8. - С. 466-476.

6. Сушанский, А. С. Анализ практического применения механизма объединения регионов на примере муниципальных образований Московской области / А. С. Сушанский, Е. П. Шитова // ГосРег: государственное регулирование общественных отношений. - 2017. - Т. 19. - № 1 (19). - С. 41.

7. Усманова, Р. М. Формы непосредственной демократии на местном уровне / Р. М. Усманова // Правовое государство: теория и практика. - 2013. - № 3 (33). С. 59-66.

8. База данных показателей муниципальных образований [Электронный ресурс]. - Режим доступа: http://gks.ru/ dbscripts/munst (дата обращения: 28.11.2018).

9. Публичные слушания сельского поселения Березняковское [Электронный ресурс]. - Режим доступа: http://www.bereznykovskoe.ru/publichn-slush (дата обращения: 28.11.2018).

10. Публичные слушания городского поселения Солнечногорск [Электронный ресурс]. - Режим доступа: http://adm-solgor.ru/public_listen/ (дата обращения: 28.11.2018).

\section{References}

1. Federal'nyi zakon ot 06.10.2003 № $131-\mathrm{FZ}$ «Ob obshchikh principakh organizatsii mestnogo samoupravleniya $v$ Rossiiskoj Federatsii» [Federal Law dated 06.10.2003 № 131-FZ "On the General Principles of the Organization of Local Self-Government in the Russian Federation»]. Available at: http://www.consultant.ru/ (accessed 28.11.2018).

2. Federal'nyi zakon ot 03.02.2015 № 8-FZ «O vnesenii izmenenii v stat'i 32 i 33 Federal'nogo zakona «Ob osnovnykh garantiyakh izbiratel'nykh prav i prava na uchastie $v$ referendume grazhdan Rossiiskoi Federatsii» i Federal'nyi zakon «Ob obshchikh principakh organizatsii mestnogo samoupravleniya v Rossiiskoi Federatsii» [Federal Law dated 03.02.2015 № 8-FZ «On Amendments to Articles 32 and 33 of the Federal Law «On Basic Guarantees of Electoral Rights and the Right to Participate in a Referendum for Citizens of the Russian Federation» and Federal Law «On General Principles of the Organization of Local Self-Government in the Russian Federation»]. Available at: http://www.consultant.ru/ (accessed 28.11.2018).

3. Ocheretina M. A. Ponyatie i tipologiya instituta publichnykh slushanii [Concept and Types of the Institute of Public Hearings], Nauchnyi ezhegodnik Instituta filosofii i prava Ural'skogo otdeleniya Rossiiskoi akademii nauk [Research Yearbook of the Institute of Philosophy and Law of Urals branch of Russian Academy of Sciences], 2008, I.8, pp. 466-476.

4. Usmanova, R. M. Formy neposredstvennoi demokratii na mestnom urovne [Forms of direct democracy at the local level], Pravovoe gosudarstvo: teoriya i praktika [The Rule of Law State: theory and practice], 2013, I.3 (33), pp. 59-66.

5. Sushanskii A. S., Shitova E. P. Analiz prakticheskogo primeneniya mekhanizma ob"edineniya regionov na primere municipal'nykh obrazovanii Moskovskoi oblasti [An analysis of the practical application of regional integration mechanism the example of municipalities of the Moscow region], GosReg: gosudarstvennoe regulirovanie obshchestvennykh otnoshenii [GosReg: government regulation of public relations], 2017, I.1 (19), p. 41.

6. Baza dannykh pokazatelei municipal'nykh obrazovanii [ $D a-$ tabase of indicators of municipalities]. Available at: http:// gks.ru/dbscripts/munst (accessed 28.11.2018).

7. Usmanova R. M. Formy neposredstvennoi demokratii na mestnom urovne [Forms of direct democracy at the local level]. Pravovoe gosudarstvo: teoriya i praktika [The Rule of Law State: theory and practice ], 2013, I. 3 (33), pp. 59-66.

8. Baza dannykh pokazatelei munitsipal'nykh obrazovanii [Database of indicators of municipalities]. Available at: http:// gks.ru/dbscripts/munst (accessed 28.11.2018).

9. Publichnye slushaniya sel'skogo poseleniya Bereznyakovskoe [Public hearings of the rural settlement Bereznyakovskoye]. Available at: http://www.bereznykovskoe.ru/publichn-slush (accessed 28.11.2018).

10. Publichnye slushaniya gorodskogo poseleniya Solnechnogorsk [Public hearings of the town of Solnechnogorsk]. Available at: http://adm-solgor.ru/public_listen/ (accessed 28.11.2018). 